\title{
NARRATIVE PRACTICES FOR COUNSELLING IN EDUCATIONAL CONTEXTS
}

\author{
Elisabetta Biffi \\ Department of Human Sciences for Education "Riccardo Massa" \\ University of Milano-Bicocca
}

\begin{abstract}
Educational contexts have their own peculiar characteristics, such as that of being multi-professional contexts with a wide range of end users. Counsellors working with educational staff must take these specifics into account. In addition, counselling should be a process that, starting out from the "core issue" that led to the decision to initiate the counselling intervention, aims to promote the professional development of educational staff. In this sense, counsellors should design their interventions to encourage meta-reflection on the context, and should themselves adopt a reflective approach.

On the basis of these key assumptions, this paper reflects on narrative practices as a resource for counselling in educational contexts, especially the practice of self-writing which also has the potential to act as a reflective tool for counsellors themselves.
\end{abstract}

Keywords. Counselling, educational contexts, journal, narrative, writing

\section{Counselling in socio-educational contexts}

Counsellors have a specific role to play in educational contexts, that is to say, within the services, bodies and organizations - both public and private - that implement educational interventions with subjects. In these contexts, care, assistance and education are provided by multi-disciplinary work teams: a variety of professionals (from psychologists to educators, social workers, healthcare workers and so on) are required to jointly construct interventions targeting a multiplicity of subjects. In the contemporary socio-educational context, marked on the one hand by a redefining of socio-educational needs and on the other by the growing crisis of the welfare system in Europe and elsewhere, educational services are faced with complex scenarios combining the emergence of new professional requirements with the attribution of multiple functions to individual staff members. This in turn leads to an even greater need for support and counselling professionals who are qualified to guide and assist educators and carers in managing and implementing their work.

The counsellor's role is complex and tricky to define; it overlaps with that of other "second level" professionals (supervisor, coordinator, trainer and similar) who support both the management of the overall service and the work conducted by educators and carers. There is ongoing debate within social science and in the arena of social policy (at least in Italy) with regard to the precise definition of the responsibilities of counsellors and the bounds within which they may legitimately intervene. Counselling has been introduced into socio-educational contexts in response to the growing complexity of their profile and mandate, and usually involves interventions that are limited (in terms of time and space) and 
specifically aimed at helping staff in a particular context to engage in metareflection on their work.

The need to call on the expertise of a counsellor may be flagged by the socioeducational workers themselves, but may also be decided by management. Broadly speaking, the need for counselling is mainly brought about by difficulty on the part of staff and of the service in general in dealing with a particular situation. In response to this, counsellors focus on the staff members in their efforts to cope with their difficulty more so than on the "problem" that led to the request for support. Thus counsellors must devise interventions that promote understanding of their clients' difficulties in the context in general, still before focusing on the theme ostensibly raised as "problematic". In other words, they are not so much required to provide solutions as to support the staff in acquiring the ability to independently construct their own solutions to their issues, declared and effective. It is critical that the staff develop the ability to recognize and identify their own difficulties. It may not be taken for granted that the problem issue initially raised coincides with the true needs of the service. Frequently, the counsellor is called in on the basis of a widespread feeling of distress that is apparently being caused by a given situation. However, the counsellor's task is to help the staff to define and understand what their needs really are. Through a process of collaboration between the external counsellor and internal participants, it is possible to identify the key underlying issues and to understand how best to gather the information required to explain what is really happening and what this implies (Schein, 1987). Recognizing and clearly defining the core issue then allows the staff themselves to identify their training and professional development needs. In other words, the counsellor's task is to reflect on what he or she observes, within the allotted time, and within the other constraints imposed by the situation, seeking out and gathering data that sheds light on the intervention context. Therefore, as specified by Shein, the counsellor's intervention may be thought of as the set of activities that he or she plans and implements with the aim of helping the client to understand and act on the events that take place in the context (Schein, 1987).

The "diagnosis" phase therefore becomes an educational opportunity to re (co-) construct the core issue(s), through dialogic modes of interaction between counsellor and staff. And, as pointed out by Bruner (1990), the structure of experience is typically "narrative". Thus, through narration, the critical scenario may be thought and recounted. This is of particular importance when counselling is being provided in educational contexts.

On what basis do we make the latter statement? An educational intervention with the explicit aim of bringing about change - is the (hi)story of a deliberately chosen educational programme, as well as of a process that happened of itself. It is very clear to those working in educational contexts that it can often be difficult to pin down one's own intervention and make it visible to others: either because it takes place over a long time-span; or because at times the change that 
actually takes place is not that which had been foreseen; or again because the process takes a different direction to that targeted by the educational intervention as planned. Nonetheless, even in the face of all these difficulties, the (hi)story dimension can be of assistance, in so far as thinking of the educational intervention in terms of a (hi)story (Biffi, 2010) combines the aspects of historicity on the one hand and narrativity on the other.

Thinking of the educational intervention as a (hi) story means, in effect, attending to the historical dimension of its enactment. It is an intervention that enters into the histories, already in existence and underway - of the clients, the service and the local area, just as it has already entered into that of the educators themselves - giving rise to a new (hi)story. In considering the historicity of the intervention, we are also reminded of the historical dimension in which it is contained: it is impossible to overlook or ignore the material, social and therefore historical context that not only frames the intervention but actually signifies it. An educational service in a small town with decades of history at its back is not the same thing as a newly set-up educational service in the suburbs of a modern city. And this is not only on account of the obvious logistical differences, but due to the different nature of the link with the local area and community, in terms of how the service is thought of and seen by others and how it sees itself.

As stated above, a biographical perspective also leads us to consider the narrativity of the intervention. Here we may view the (hi)story as an account or story that, as narrative studies have shown, has a beginning, a middle and an end, and may be told. Therefore, thinking of the educational intervention as a narrative means attributing it with a beginning, a middle and some kind of end point. This aspect is important but challenging for educators, for whom time represents both a constraint and an opportunity. Some interventions begin and end at strictly prescribed times (for example, work with minors in third-party custody), others begin gradually and finish abruptly (for example in street education contexts), while still others are protracted over time without producing observable change (such as when the intervention becomes chronic). But the story is a narrative demanding to be told, an artistic event that becomes concrete as it unfolds. These are not trivial aspects: educators are often asked to account for the result or product rather than for the process, despite the fact that in educational interventions the process is the true product. For example, it is not very meaningful to report that the result of our intervention is that the child in our care has finally begun to pack its own school bag if this outcome is stripped of its story. It is somewhat like describing a detective novel by saying that the murderer was the butler: by taking away the plot of the novel, we lose the novel itself. Therefore, the educational intervention too needs to be recounted, with its elements of suspense, unexpected failures and unforeseen outcomes. It offers changes of scene and dramatic turns of events, both predefined sets and improvised scenarios. In some ways therefore, a planned educational 
intervention is a template that may be modified, a rough script that is yet to be interpreted.

Furthermore, narrating the plot also facilitates the shift from naive to critical thinking, where critical thinking is understood as the ability to make visible and to spatialize, through writing - the complex educational weave, providing others with the opportunity to identify its knots and tears. It is therefore a type of narrating that becomes sharing and rethinking the intervention and - during the implementation stage - remaining conscious of the requirement to report on it.

Yet there is little tradition of reporting on educational processes by narrating them; of course this does take place informally amongst team members who share their life stories with one another, but this sharing is neither documented nor taken into account for evaluation purposes. It is as though the (hi)story of an educational intervention is something private that takes place within the educational relationship, and of which only the actors themselves have knowledge and awareness. However, this approach deprives the service and the local community of an understanding of the process. It relegates educational action to the sphere of magical and mysterious events, treating it as an alchemy of sensations that cannot act as a model. In reality, this is quite understandable. Provided, however, that we do not throw out our witness along with the model: stated differently, the need for education professionals and educational services to think and tell the (hi)stories of their educational interventions is not based on the logic of the model but on that of witness. By witness we mean something that attests to the very existence of the educational relationship but also that of the user and the service, by linking them to a recognizable and shared plot. That is to say, something that redeems the educational experience from the disposability of the immanent.

Within such a perspective, the challenge is learning to think of counselling as an intervention that helps to think and narrate processes. To do so, the counsellor requires specific training that includes writing as a key component.

\section{Writing to think}

As stated above, the role of counsellors is to guide educational services through personalized processes of reflection and analysis, in such a way that staff are agents in the process from identification of the core issues through the planning and implementation of solutions. As Bruner (1990) observes, reality is constructed through acts of meaning on the part of the narrator, and this also holds true for reflection. Thus pedagogical work (Riva, 2004) comprehends a process of searching for meanings and of listening to and interpreting the dynamics currently in play. The role of counsellor therefore does not merely consist of breaking down a complex situation into simpler components: on the contrary, it involves attributing value to the complexity of the context. Ultimately, counsellors carry out their work within the subjects' process of 
attributing meaning to their own experience. Their job is to facilitate educational staff in understanding the framework of meaning within which they have defined their "problem". In other words, counsellors seek to identify the "local theories" underpinning individual theories on the world in general and specifically on the current crisis: "Local theories are a need of the individual, determined by the very way in which we think, acquire knowledge and act" (Fabbri, 1990, p. 33).

Narration is an intimate and personal search for the right and most meaningful words to express one's thinking; it requires the patience of a composer who combines individual sounds interspersed with pauses in the search for a harmonious whole. Words, as Demetrio comments, "describe, transform, arouse emotions, investigate, evoke, impress and do good" (Demetrio, 1996, p. 155).

In promoting such a process, counsellors may avail of a particularly useful reflective instrument: writing. The value of writing in the training of education professionals is well-established: whether autobiographical writing (Formenti, 1998), writing as a reflective practice (Mortari, 2003) or as a means of making explicit one's own professional activity (Canevaro, Chiantera, Cocever, \& Perticari, 2005). However, writing is not limited to these areas: it is also a highly appropriate tool for the counsellor. Indeed writing, given its recognized selfeducational nature, even when it is not focused on self-narration but for example used to construct knowledge, represents the relationship between care and knowledge that is characteristic of human nature itself. Words are the intimate channel of expression of the inner life, and have constituted since ancient times the first and most instinctive practice of care. Writing is care of the self because it is an act of becoming aware, of taking on responsibility for the world and for others; it implies recognizing how the self is formed and reflecting on this in order to modify it. Writing is therefore a "practice" particularly in the sense of a living practice: thus when we refer to "pratice", we refer to an event, an opening up to meaning, an opening up to the world" (Sini, 1994, p. 78), a practice of thinking. It is this subtle link between thinking and writing that endows the latter with the status of logos, or structured discourse. While it is not possible to conceive of thinking without words (Arendt, 1978), it is also true that thinking needs words to produce the world: writing has the power to create thought and at the same time to bring the world inside itself; in writing, one takes possession in a certain sense of the thing one is thinking about (Foucault, 2001).

Thus, writing about self, in its many forms, becomes a space for meta-reflection, and an opportunity to think about the process of thinking itself. The form chosen to write about the self is therefore not only a medium but also a meaning. Subject and meaning are intertwined, as theorized at length by Ricoeur, which in turn raises the hermeneutic issue of interpretation of the written text: a given text presents a «proposed world» (Ricoeur, 1986).

In these terms, writing is simultaneously a research instrument and a means of intervention: it inevitably sets off processes of reflection and of metacognitive 
thinking, as is always the case when someone is invited to think about their own thinking let alone write about it. Writing about self, in this view, gives a creative impulse to the search for, and re-creation of, a framework of meaning for one's own life history. As Winnicott (1971) might express it, self-writing is the creative apperception that makes one feel that life is worth living. Otherwise, the world would appear to us as something we have to adapt to or fit into.

\section{The journal as a tool for the counsellor}

If we wish to fully harness the reflexive power of writing, the journal is a key instrument to be adopted. In all its variations, it is a practice that lends itself to use as an instrument of both witness and reflection. In order to grasp the nature of witness provided by keeping a journal, it is sufficient to think of its use in ethnographic contexts, as well as in the social sciences in general, in which it preserves the memory of the data gathered. At the same time, within the private writing tradition, the journal or diary is also the place in which intimate and secret thoughts are recorded. Therefore the counsellor that keeps a journal, does so as a professional who is making conscious use of writing to pin down the process that is unfolding, but also to listen to what he or she is hearing, and to hone in on daydreams that may provide insights into the context. At the same time, as a self-analytical space for critical thinking, the journal is an instrument for reinterpreting past events and planning future ones, in other words for guiding the intervention as it develops.

Journal writing therefore becomes an exercise in listening to both self and others that ultimately provides a ongoing means of supervision and self-training for the professionally trained listener. Furthermore, it is often thought that the counsellor's intervention only takes place in the educational situation itself, during contact with the educational staff and service: on the contrary, journalkeeping leads the counsellor to engage in reflection both before and after each encounter, in the time and space suspended between encounters in which the process may be reviewed and future steps weighed up. The latter aspect introduces a further valuable use of journal writing for the counsellor, that is to say, as a means of evaluating his or her own intervention.

One might be inclined to view appraisal of counselling as being the same thing as evaluating the actions fostered by the counsellor (that is to say, the final outcome of the "problem" that led to the counselling intervention being initiated in the first place).

However, if the counselling intervention is thought of as a meta-reflective process with educational outcomes for the staff involved, appraisal takes on new meanings. Specifically, evaluating the educational efficacy of the consultancy process means evaluating how that process contributed to the professional development of the clients. At the same time, the educational staff that received the counselling are also called upon to evaluate the process, in recognition of the 
self-training capacities of adults and of the educational value of the counselling intervention.

Furthermore, if we view counselling as joint construction of a (hi)story, then narrative tools should also be used to evaluate it. Thus, on concluding their interventions, counsellors could provide staff with narrative prompts such as open questions, selected readings or autobiographical writing in order to promote narrative construction of the intervention and consequently to make it the object of further reflection. When this kind of writing is shared in the work group, it may be used by the counsellor not to put forward interpretations but to illustrate to the group the potential inherent in observing things from different viewpoints; in practice this implies valuing the plurality of perspectives present in a work group and increasing each member's sense of responsibility for his or her own perspective. In this way, the evaluation phase becomes a further search for meanings in terms of the new perspectives acquired and the intertwining of staff members' experiences during the intervention itself.

\section{Conclusions}

If this aspect of counselling is to be developed to its maximum potential, it is of the utmost importance that counsellors' own training include a self-writing component. Before asking someone else to narrate themselves, it is critical to understand for oneself what this kind of narration implies. What does narrating oneself to another person, particularly to another party that detains "power" in a given situation, mean? Self-narrating (Demetrio, 1996) has both emotional and cognitive implications that need to be experienced firsthand. Just as psychotherapists are required to undergo a course of therapy as part of their training, so too counsellors who wish to make use of narration in a mindful way should themselves undergo training through narration. Such an exercise helps them to grasp what it means to think in narrative terms but also how to write about others. Writing their own (hi)story may therefore provide a training experience for counsellors that leads them to weigh up their own histories and professional motivation; this in turn may promote the construction of the critical thinking that the work of a counsellor demands. Furthermore, the writing exercise may allow them to experience in due proportion how individuals feel when asked to self-narrate; this is of value because counsellors in the course of their own professional work will ask their clients to narrate and self-narrate.

In conclusion, when used to explore and acquire an understanding of the meanings and experiences making up a need, writing is a valuable research instrument because it facilitates the re-elaboration of complex situations as outlined here. Writing is therefore a space in which to speak out, a coming out into the world. Writing is care because it enables effective communication and the building of bridges - and therefore relationships - where silence previously concealed the inability to speak; however it is also care because it provides the 
opportunity to take one's time, to seek a personal pace that is in sync with the pace of one's feelings, whereby silence is no longer a constraint but has become a valued companion that may be freely chosen.

\section{Summary}

Educational contexts present peculiar characteristics: they are multi-professional contexts, with a wide range of end users. The growing complexity of contemporary society has presented socio-educational services with new social needs and challenges. Due to this complexity, those working in the socio-educational services are required to fulfil more than one role and function, leading to increasing confusion regarding their professional profile.

Counselling in educational contexts must take these specifics into account. In addition, counselling should be a process that, starting from the "core issue" that led to counselling being initiated, aims to promote the professional development of educational staff.

The counsellor's role is not to provide solutions to problems but to help staff acquire a deeper understanding of the issues and discover new professional needs that they might not have previously identified. In this sense, counsellors should design their interventions to foster meta-reflection on the context, and should themselves adopt a reflective approach. Interventions by counsellors should be based on observation of the situation, and on analysis of the information to be collected to enable appropriate actions to be planned. Finally, counsellors need to adopt a self-reflective approach, so as to take their own viewpoint into due account.

On the basis of these key assumptions, the current paper reflects on narrative practices as a resource for counselling in educational contexts, particularly self-writing practice which may also provide a reflective tool for counsellors themselves.

In effect, writing is a practice that enables writers to attain a different level of understanding of reality. This is because, as Bruner has emphasized, people structure their experiences narratively. In this sense, recounting reality is a way to think of reality.

Writing practices may be a way to generate the meta-reflection required to broaden current understanding of the situation and of staff needs and, in particular, may shed light on the subjective perspectives feeding into the definition of the "problem". This paper explores a particular kind of writing practice, journal writing, when used as a space and time in which to think about the counselling situation and plan future action.

\section{Bibliography}

1. Arendt, H. (1978). The Life of the Mind. New York: Harcourt Brace \& Company.

2. Biffi, E. (Eds.) (2010). Educatori di storie. Milano: FrancoAngeli

3. Bruner, J. (1990). Acts of Meaning Cambridge, MA: Harvard University Press.

4. Demetrio, D. (1996). Raccontarsi. L'autobiografia come cura di sè. Milano: Raffaello Cortina.

5. Formenti, L. (1998). La formazione autobiografica. Confronti tra modelli e riflessioni tra teoria e prassi. Milano: Guerini Studio.

6. Foucault, M. (2001). L’herméneutique du sujet. Paris: Seuil-Gallimard. 
7. Fabbri, D. (1990). La memoria della regina. Pensiero, complessità, formazione. Milano: Guerini e Associati

8. Mortari, L. (2003). Apprendere dall'esperienza. Il pensare riflessivo nella formazione. Roma: Carocci.

9. Ricouer, P.

10. Riva, M.G. (2004). Il lavoro pedagogico. Come riceca dei significati e ascolto delle emozioni. Milano: Guerini Studio.

11. Schein, E.H. (1987), Process Consultation (volume 2): Lessons for Managers and Consultants. Massachusetts: Addison Wesley

12. Sini, C. (1994). Filosofia e scrittura. Roma: Laterza.

13. Winnicott, D. (1971). Playing and Reality. New York: Basic Books.

\begin{tabular}{|l|l|}
\hline Elisabetta Biffi & Department of Human Sciences for \\
& Education "Riccardo Massa" \\
& University of Milano-Bicocca \\
& e-mail: elisabetta.biffi@unimib.it \\
& tel.: +39064484859 mobile: +39 \\
& 3397312769 \\
\hline
\end{tabular}

